\title{
The Hull Strength of Marine Current Turbine Platform
}

\author{
Achmad Baidowi ${ }^{1}$, Irfan Syarif Arief ${ }^{2}$, Lintang Candra $^{3}$
}

\begin{abstract}
Strength analysis of hull structure of marine renewable energy is crucial. The hull structure must be able to whitstand the harsh environmental load such as wave, wind and the weight of the payload and the structure itself. This paper analyzies the structural hull strength of marine current turbine platform. The platform is held by 4 mooring lines in $200 \mathrm{~m}$ water depth. The hull material is AISI1050 with yield stress 530MPa, the analysis consist of stress analysis which consider the dynamic motion of the platform due to wave, current, win and mooring line tension. The dynamic motion shows the maximum gravity acceleration is $1.3496 \mathrm{G}$. The gravity acceleration creates additional loads due to weight multiplication of payload and structure. From the dynamic analysis using numerical software, the maximum mooring line tension due to dynamic analysis is $300.74 \mathrm{kN}$ and this tension will creates stress in the moring line connection structure in the platform hull. The maximum stress of the is 126.045Pa, The mooring line tension is the highest loads compared to other factors such as weight. The safety factor of the structure based on the analysis is 4.2 which can be calculated by comparing the yield stress of the hull material and the maximum stress occurred due to dynamic load.
\end{abstract}

Keywords—Hull stress, Dynamic load, Marine Current turbine.

\section{INTRODUCTION}

$\mathrm{D}$ ifficult access to service and installation of electricity network in remote island become the cause of uneven distribution of electricity network, so need to get more attention in facing the problem. The ocean area of Indonesia is ore than $70 \%$ which provide enormous energy resource [1]. Some energy sources of the ocean can be form of wave, current, offshore wind and current [1].

In order to harness the ocean renewable energy sources, it is necessary to develop design of marine renewable energy system. One of the source is the marine current energy. This paper will analyse the marine current energy platform in deep water. Since the system tend to become more unstable compared to shallow water [2]. Therefore, it is very important to analyse floating platform hull design and construction.

The floating platform hull and construction is the main requirement that must be emphasized because it must withstand various dynamic load such as wind, wave and current [3].

This paper analyses the stress of quadrimaran marine current energy platform due to dynamic loads and mooring line tension.

Achmad Baidowi, Department of Marine Engineering, Institut Teknologi Sepuluh Nopember, Surabaya 60111, Indonesia, Email : ahmadbai@gmail.com

Irfan Syarif Arief, Department of Marine Engineering Institut Teknologi Sepuluh Nopember, Surabaya 60232, Indonesia, Email : irfansya@gmail.com

Lintang Candra, Department of Marine Engineering, Institut Teknologi Sepuluh Nopember, Surabaya 60111, Indonesia, Email : candra.lintang1@gmail.com

\section{METHOD}

\section{A. Numerical model of Platform Hull}

The platform numerical model is built using 3D computer modeling software. This paper discusses the quadrimaran platform for deep water marine current turbine system (MCT) [3]. it is built using AISI 1050 material which has displacement 44 tones. The design of the platform can be shown by Figure.1.

The construction of the hull is still constructed based on the offshore construction regulation and ship classification, this is due the lack of information of construction regulation of marine renewable energy. The plate and other structural member modelled in 3D, this allows the platform to be analyzed using Finite Element Analysis (FEA) software.

\section{B. Motion Analysis}

The analysis is conducted in 6 Degree of Freedom (DOF) using numerical software which apply panel method. Motion analysis initiated with Response Amplitude Operator (RAO) analysis, the RAO allows us to analyze the motion characteristic of the platform in the early stage of design. RAO also can be used as input for the dynamic load analysis for mooring tension and to find the value of the gravity accelaration due to the dynamic motion [5]. The motion and mooring analysis uses MOSES software.

The dynamic load which generated from the environmental load are variated based on the heading direction. The variation of heading direction is $0^{\circ}, 45^{\circ}$, $90^{\circ}, 135^{\circ}, 180^{\circ}$.

\section{Hull Strength Analysis}

The results of the mooring tension used as input in the hull strength analysis using FEA software. The loads used in this paper are structural weight load, payload, dynamic load and mooring tension. 


\section{RESULTS AND DISCUSSION}

A. Numerical Model of Platform
The motion analysis results shows the maximum RAO values in six DOF can be shown by Table 2 .

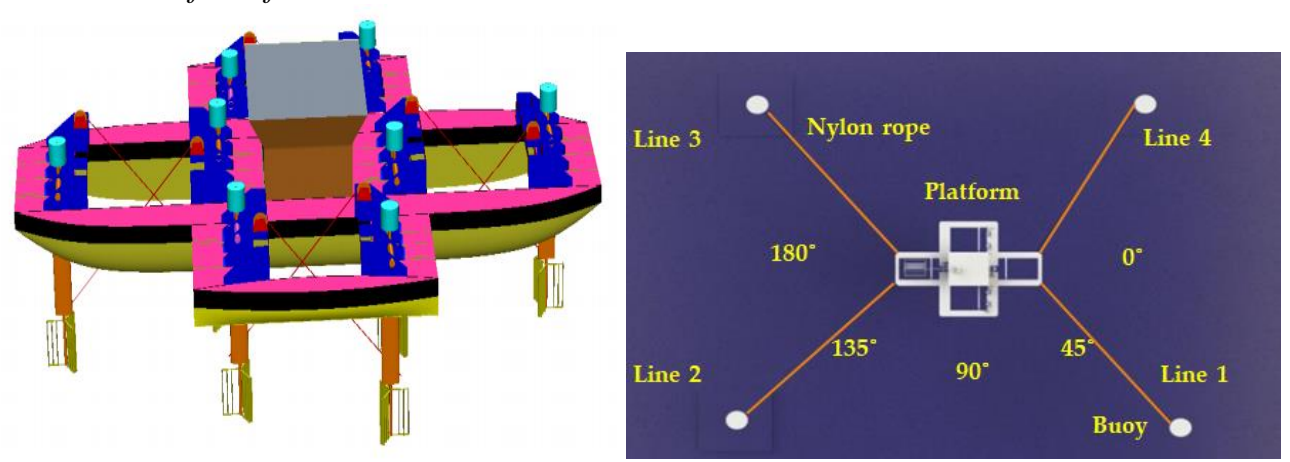

Figure. 1. Quadrimaran Platform

The platform numerical model is built using 3D computer modeling software. This paper discusses the quadrimaran platform for deep water marine current turbine system (MCT) [3]. It is built using AISI 1050 material which has displacement 44 tones. The design of the platform can be shown by Figure.1. The platform consist of 8 vertical axis MCT and the dimensions are shown in Table 1. The platform is held by four mooring lines supported by floater buoy.

The weight distribution are calculated based on the structural member of the hull and equipment onboard of the platform or payload.

The weight is distributed into 40 stations along the platform.

TABLE 1 .

MAIN DIMENSION

B. Motion Analysis.

Based on the motion analysis conducted in numerical software, the maximum RAO values in six DOF can be shown in Table 2.

\begin{tabular}{ccc}
\hline Main dimension & Main Hull & Stager \\
\hline Lpp & $20 \mathrm{~m}$ & $8 \mathrm{~m}$ \\
$\mathrm{~B}$ & $1.25 \mathrm{~m}$ & $0.85 \mathrm{~m}$ \\
$\mathrm{H}$ & $1.75 \mathrm{~m}$ & $1 \mathrm{~m}$ \\
$\mathrm{D}$ & $1.25 \mathrm{~m}$ & $0.53 \mathrm{~m}$ \\
$\mathrm{Cb}$ & 0.125 & 0.51 \\
Displ & $20.435 \mathrm{~m}^{3}$ & $1.604 \mathrm{~m}^{3}$ \\
\hline
\end{tabular}

Analysis of motion shows that the highest rotational motion is roll motion which occurred in $90^{\circ}$ heading where the values. While the translational motion values is heave. The values are $30.25 \mathrm{deg} / \mathrm{m}$ for roll and 1.08 $\mathrm{m} / \mathrm{m}$

for heave.

Table 2.

MAXIMUM RAO

Surge $(\mathrm{m} / \mathrm{m}) \quad$ Sway $(\mathrm{m} / \mathrm{m}) \quad$ Heave $(\mathrm{m} / \mathrm{m}) \quad$ Roll $(\mathrm{deg} / \mathrm{m}) \quad$ Pitch $(\mathrm{deg} / \mathrm{m}) \quad$ Yaw $(\mathrm{deg} / \mathrm{m})$

\begin{tabular}{lcccccc}
\hline Heading $0^{\circ}$ & 0.97 & 0 & 0.15 & 0 & 8.96 & 0 \\
Heading $45^{\circ}$ & 0.69 & 0.7 & 0.56 & 1 & 8.42 & 3 \\
Heading $90^{\circ}$ & 0 & 1 & 1.08 & 30.25 & 0 & 0 \\
Heading $135^{\circ}$ & 0.69 & 0.7 & 0.56 & 1 & 8.42 & 3 \\
Heading $180^{\circ}$ & 0.97 & 0 & 0.15 & 0 & 8.96 & 0 \\
\hline
\end{tabular}

\section{Mooring Tension Analysis}

Based on the motion analysis, the mooring line tension can be generated using numerical software. The mooring line analysis conducted in collinear heading where the direction of wind, wave and current is in the same direction. There are six directions as mentioned in Table 2.
The results of mooring line analysis can be shown in Figure 2 for 0 and 45 heading, 3 for 90 and 135 heading and 4 for 180 heading.

The mooring line consist of two segments, the nylon segment which connected the platform and the floater buoy and chain connect the floater buoy to seabed.

Based on the simulation the maximum mooring line tension which connected to hull $273.04 \mathrm{kN}$ in nylon line. 


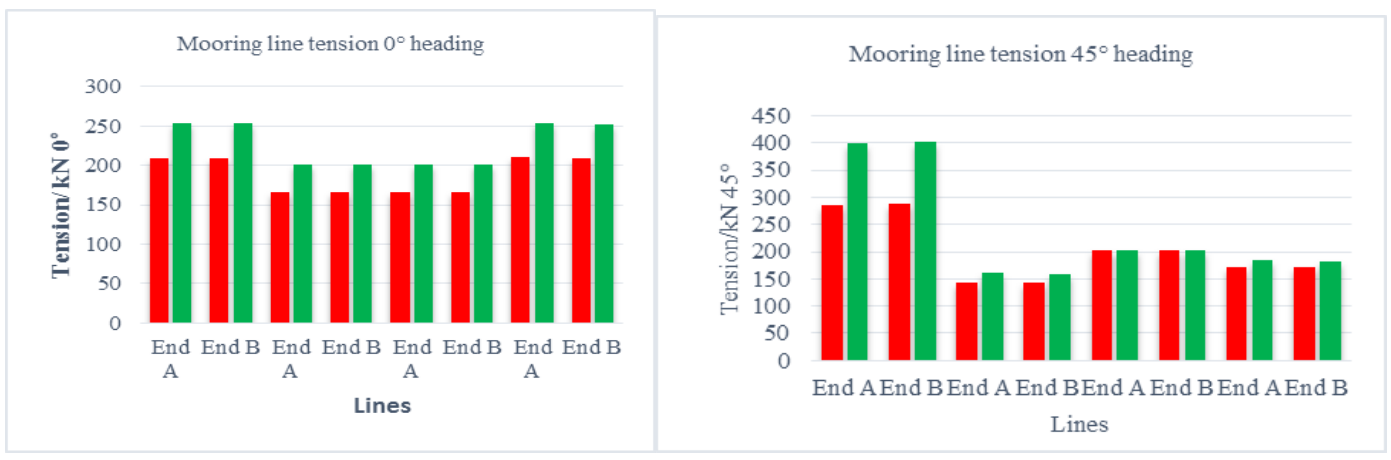

Figure. 2. Mooring Tine Tension Heading 0 and 45
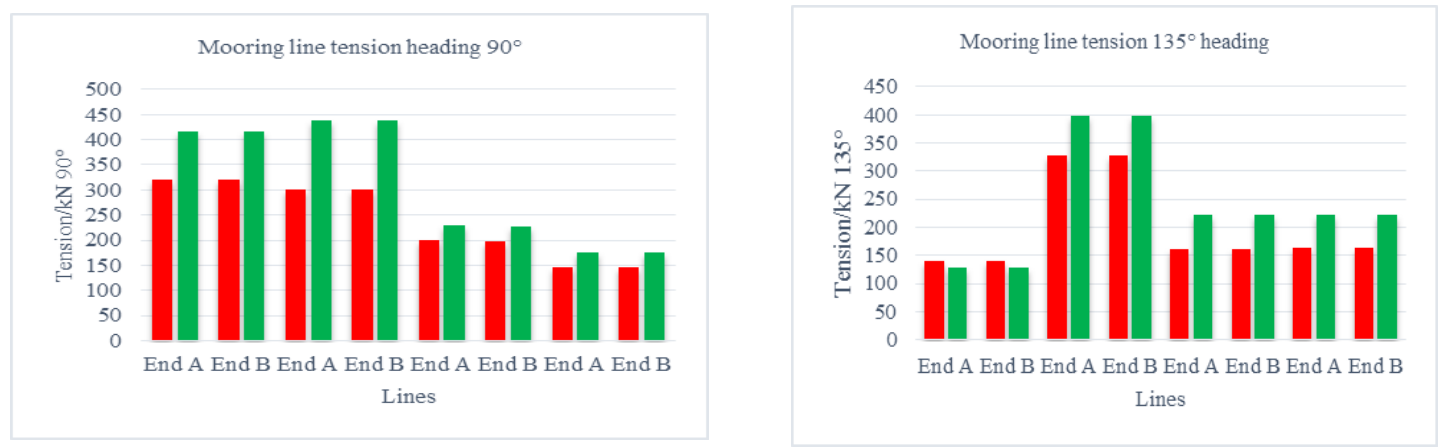

Figure. 3. Mooring Tine Tension Heading 90 and 135

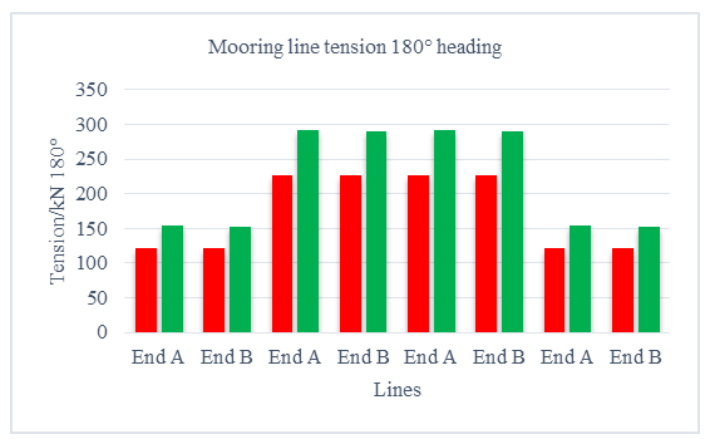

Figure. 4. Mooring Tine Tension Heading 90 and 135

\section{Hull Strength Analysis}

In order to analyze the structural strength of the hull, the critical value of forces are applied to the hull. The accumulation force applied to the hull is $404.56 \mathrm{kN}$ for

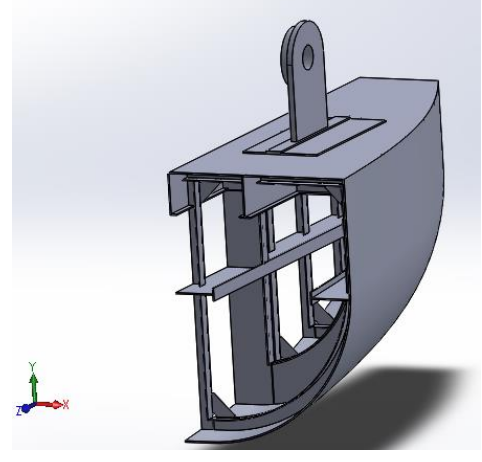

Figure 5. FEA Model of Hull

Figure 5. (Right) shows the stress distribution along the hull based on the payload, mooring line tension and dynamic loading. The highest stress of hull skin is 42.18 buoyancy and $273.04 \mathrm{kN}$ for mooring line tension. The FEA model of the structural assessment is shown in Figure 5.

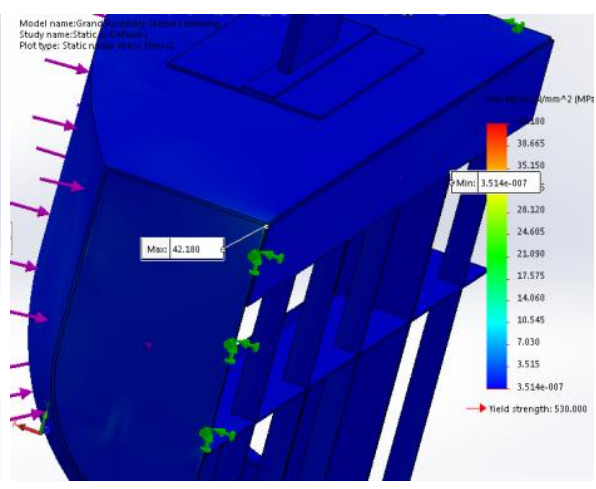

Mpa. While the maximum deformation occurred is $0.231 \mathrm{~mm}$ which can be shown by Figure 6 . 


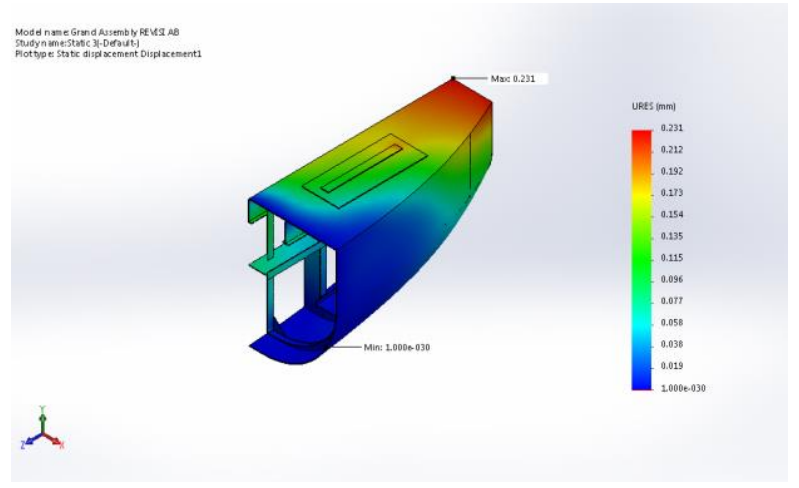

Figure 6. Hull Deformation

The structural member maximum stress is $126.045 \mathrm{kN}$ which occured in the T Profile of the hull structural

\section{CONCLUSIONS}

From the several results of simulation, there are several conclusions which can be addressed:

1) The highest stress in structural member is $126.045 \mathrm{kN}$ which still far from the yield stress of the AISI 1045 Material.

2) The highest stress of the hull is $404.56 \mathrm{kN}$ which still under the yield stress of AISI 1045 material.

3) Based on the ABS regulation it still can be categorized that the hull structural strength is safe but a different regulation must be setup since the size of the Ocean renewable energy platform is smaller compared to FPSO.

\section{REFERENCES}

[1] Quirapas et.al, (2015). Ocean Renewable Energy in South East Asia: A Review, Renewable and Sustainable Energy Reviews. 41 pp:799-817. member. The strength assessment is using ABS Standard for FPSO.

[2] Roberts et.al, 2016, Current tidal power technologies and their suitability for applications in coastal and marine areas J. Ocean Eng. Mar. Energy 2:227-245.

[3] Semin, Baidowi, Arief R.S, 2017, Analysis of the Deep Water Mooring System Platform, Marine Technology Conference (SENTA), Surabaya, Indonesia.

[4] Hao Yu Xiaoyu Li and Shuguang (2012) Yang. Dynamic Analysis Method of Offshore Jack-up Platforms in Regular and Random Waves. College of Shipbuilding Engineering, Harbin Engineering University, Harbin 150001, China 2. Research Center, American B.

[5] Paul d. Ronney (2014). Basics of mechanical engineering. integrating science, technology and common sense department of aerospace and mechanical engineering university of southern California.

[6] ABS, 2014, RULES FOR BUILDING AND CLASSING, FLOATING PRODUCTION INSTALLATIONS,Houston TX,USA. 